\title{
The Shiga toxin 2 B subunit inhibits net fluid absorption in human colon and elicits fluid accumulation in rat colon loops
}

V. Pistone Creydt,

M. Fernandez Miyakawa*, F. Martín*, E. Zotta,

C. Silberstein and C. Ibarra
Laboratorio de Fisiopatogenia, Departamento de Fisiología,

Facultad de Medicina, Universidad de Buenos Aires, Buenos Aires, Argentina

\section{Correspondence \\ C. Ibarra \\ Departamento de Fisiología \\ Facultad de Medicina \\ Paraguay 2155, 7 mo piso \\ Caja Postal 1121 \\ Buenos Aires \\ Argentina \\ Fax: +54-11-4508-3653 \\ E-mail: ibarra@fmed.uba.ar \\ Research supported by Universidad de Buenos Aires (TM28/01, Consejo Nacional de Investigaciones Científicas y Técnica (CONICET; PIP-867/98), Agencia Nacional de Promoción Científica y Tecnológica (PICT-9508/01), and Ministerio de Salud de la Nación \\ (Beca Carrillo-Oñativia 2000/01). \\ *These authors contributed equally to this study.}

Received August 21, 2003

Accepted February 26, 2004

\begin{abstract}
Shiga toxin (Stx)-producing Escherichia coli (STEC) colonizes the large intestine causing a spectrum of disorders, including watery diarrhea, bloody diarrhea (hemorrhagic colitis), and hemolytic-uremic syndrome. It is estimated that hemolytic-uremic syndrome is the most common cause of acute renal failure in infants in Argentina. Stx is a multimeric toxin composed of one A subunit and five B subunits. In this study we demonstrate that the Stx2 B subunit inhibits the water absorption (Jw) across the human and rat colonic mucosa without altering the electrical parameters measured as transepithelial potential difference and short circuit current. The time-course Jw inhibition by $400 \mathrm{ng} / \mathrm{ml}$ purified Stx2 B subunit was similar to that obtained using $12 \mathrm{ng} / \mathrm{ml} \mathrm{Stx} 2$ holotoxin suggesting that both, A and B subunits of Stx2 contributed to inhibit the Jw. Moreover, non-hemorrhagic fluid accumulation was observed in rat colon loops after $16 \mathrm{~h}$ of treatment with 3 and $30 \mathrm{ng} / \mathrm{ml} \mathrm{Stx2} \mathrm{B} \mathrm{subunit.} \mathrm{These} \mathrm{changes} \mathrm{indicate} \mathrm{that} \mathrm{Stx2}$ $\mathrm{B}$ subunit induces fluid accumulation independently of A subunit activity by altering the usual balance of intestinal absorption and secretion toward net secretion. In conclusion, our results suggest that the Stx2 B subunit, which is non-toxic for Vero cells, may contribute to the watery diarrhea observed in STEC infection. Further studies will be necessary to determine whether the toxicity of Stx2 B subunit may have pathogenic consequences when it is used as a component in an acellular STEC vaccine or as a vector in cancer vaccines.
\end{abstract}

Key words

- Hemolytic-uremic

syndrome

- Diarrhea

- Shiga toxin 2

- B subunit

- Water transport

\section{Introduction}

Shiga toxin-producing Escherichia coli (STEC), an important and emergent pathogen with various serotypes including O157:H7, has been linked to a spectrum of disorders, including watery diarrhea, bloody diarrhea (hemorrhagic colitis), and hemolytic-uremic syndrome (HUS) $(1,2)$. The virulence of these strains is determined to a large extent by the production of Shiga toxin type 1 (Stx1) and/or Shiga toxin type 2 (Stx2).

In Argentina, E. coli serogroup O157 bacteria expressing both Stx1 and Stx2 are 
the microorganisms most frequently isolated from children with HUS, although strains that express only Stx 2 are also highly prevalent $(3,4)$. Both Stx 1 and Stx 2 are multimeric toxins composed of an approximately 32$\mathrm{kDa}$ A subunit protein in noncovalent association with a pentameric ring of identical B subunit proteins, each with a molecular mass of approximately $7.7 \mathrm{kDa}$. Toxin binding to cells is mediated by B subunits, which bind to the globotriaosylceramide (Gb3) glycolipid receptor present on the plasma membrane of certain eukaryotic cells (5).

After binding to $\mathrm{Gb3}$, the holotoxin is endocytosed via a clathrin-dependent mechanism (6) and trafficking to the endoplasmic reticulum, leading to translocation of the enzymatic A subunit to the cytosol where it catalyzes depurination of a single adenine residue in the 28S rRNA of 60S ribosomes, resulting in inhibition of protein synthesis (7). If protein synthesis is completely inhibited, cell death eventually occurs, and Stx may cross the intestinal barrier to mediate the vascular complications of disease including hemorrhagic colitis and HUS. Such cellular destruction may occur either through the effects of the Stx on protein synthesis or as consequence of other pathological processes, such as apoptosis. Recently, it has been shown that Stx1 and Stx2 trigger signaling events that lead to apoptosis or programmed cell death in intestinal cells $(8,9)$ which decreases barrier function (10) and could provide a mechanism for Stx to enter the bloodstream. However, there are other possible routes that Stx may take, including translocation across intestinal epithelial cells in an energy-dependent and saturated manner (11). Therefore, the variation in disease in response to Stx could be a consequence of different pathways and mechanisms involved in its movement through the intestinal epithelial cell barrier.

Studies on intestinal models have suggested that Stx can modulate disease severity, including the production of diarrhea and hemorrhagic colitis. Intraintestinal inoculation of rabbits with Stx and STEC has been used as a model of both hemorrhagic colitis and HUS (12). Inoculation of purified Stx 1 from E. coli $\mathrm{O} 157: \mathrm{H} 7$ into ligated ileum segments of adult rabbits induced fluid accumulation in association with the presence of apoptotic intestinal villous epithelial cells (13). Crude and purified Stx 2 holotoxin also significantly inhibited the absorptive water transport across human colon in vitro (14) and evoked fluid accumulation in a rat colon loop in vivo, events associated with damage to the colonic epithelial cells (15). Although the contribution of the Stx A subunit to the induction of these events has been demonstrated using the entire holotoxin, it is not clear if the Stx B subunit may be able to exert any effect on enterocyte function. The B subunit possesses signaling properties in its own right that can cause apoptosis of cells expressing the Gb3 receptor. In 1993 it was discovered that the B pentamer of Stx1 triggers apoptosis in Burkitt's lymphoma B cells, albeit at a much higher concentration than did the holotoxin (16), whereas the Stx2 B subunit triggers apoptosis in the Ramos but not in the Daudi Burkitt's lymphoma B-cell line (17). Other reports also showed that the Stx1 B subunit is non-toxic when applied to HeLa (18), Vero (19) or monocytic THP-1 (20) cells. However, to date, no studies have determined a biological action of the Stx2 B subunit on human colonic mucosa.

The purpose of the present study was to examine the effects of the Stx2 B subunit on water and ion transport in colonic epithelial cells in order to better understand the mechanism by which STEC induces diarrhea. We report here that the Stx2 B subunit inhibited water absorption in human colonic mucosa in vitro and elicited fluid accumulation in rat colon loops in vivo. We therefore suggest that the Stx2 B subunit is able to induce watery diarrhea and to contribute to the dysenteric syndrome independent of the presence of the active A subunit. 


\section{Material and Methods}

\section{Plasmid construction}

Standard techniques were used to construct different expression plasmids (21). Plasmids were isolated from the bacteria using the Wizard Plus SV miniprep DNA purification system (Promega Corp., Madison, WI, USA). All constructs were sequenced by the dideoxy chain-termination method using an Applied Biosystem automatic sequencer.

The stx $2 a$ and $b$ genes were obtained from chromosomal DNA of E. coli C600 containing the $933 \mathrm{~W}$ bacteriophage (22) (a gift from M. Rivas, Instituto Nacional de Enfermedades Infecciosas "Dr. Carlos G. Malbrán”, Buenos Aires, Argentina). A fragment of $1422 \mathrm{bp}$ was amplified by the polymerase chain reaction (PCR) from chromosomal DNA using two specific primers (upstream: 5'-GAA TTC ATT ATG CGT TGT TAG-3' and downstream: 5'-GAA TTC TCA GTC ATT ATT AAA CTG-3', both containing an EcoRI restriction site) flanking both the $s t x 2 a$ and $b$ genes. The PCR product was cloned into pGEM-T Easy (Promega). Competent $E$. coli $\mathrm{DH} 5 \alpha$ cells (Life Technologies, Rockville, MD, USA) were transformed and the isolated plasmid was designated $\mathrm{pStx} 2$. The $s t x 2 b$ gene, including its native leader peptide coding sequences, was amplified by PCR from E. coli C600 (933W) by using two primers (upstream: 5'-GAA TTC ATG AAG AA ATG TTT ATG GCG-3' and downstream, same as above). The 282-bp fragment was ligated into pGEM-T Easy and E. coli $\mathrm{DH} 5 \alpha$ was transformed. The isolated plasmid was named $\mathrm{pStx} 2 \mathrm{~B}$. A recombinant E. coli containing a mutation in $\mathrm{Stx} 2$ was obtained by deleting $90 \%$ of the Stx 2 A gene. Briefly, pStx2 was hydrolyzed by SmaI and StuI (corresponding to positions 305 and $1102 \mathrm{bp}$, respectively) and religated. The plasmid thus obtained (pStx $2 \Delta \mathrm{A}$ ) was introduced into E. coli DH5 $\alpha$. Sequence analysis of this construct showed deletion of the stx $2 a$ gene, while the whole $s t x 2 b$ gene was left intact. $E$. coli containing pGEM-T carrying a non-related sequence was used as a negative control (E. coli control).

Cultures of recombinant E. coli (pStx2), E. coli (pStx2B), E. coli (pStx2 $\Delta \mathrm{A})$ and $E$. coli (control) were obtained by incubation overnight at $37^{\circ} \mathrm{C}$ with shaking at $200 \mathrm{rpm}$ in $5 \mathrm{ml}$ of Luria-Bertani (LB) broth (Difco Laboratories) supplemented with $100 \mu \mathrm{g} / \mathrm{ml}$ ampicillin (Sigma Aldrich Co.). Bacterial cells were then removed by centrifugation and the resultant supernatants were filtersterilized through $0.22-\mu \mathrm{m}$ pore size filter units (Millipore Corp.) and assay by stx 2 expression.

In order to purify the Stx 2 B subunit, the $s t x 2 b$ gene was amplified by PCR using $\mathrm{pSt} \times 2 \mathrm{~B}$ as template and specific primers containing Sph1 and BamH1 restriction enzyme sites. The $s t \times 2 b$ gene was then fused in frame with the 6XHis tag gene using the pQE-70 vector (QIAGEN) to create an Stx2 B-His fusion protein. The plasmid thus obtained (pStx2B-His) was introduced into E. coli DH5 $\alpha$.

\section{Purification of the Stx2 B subunit}

The Stx2 B subunit was purified by affinity chromatography under native conditions. Briefly, recombinant E. coli containing $\mathrm{pStx} 2 \mathrm{~B}$-His were cultured by incubation overnight at $37^{\circ} \mathrm{C}$ with shaking at $200 \mathrm{rpm}$ in $20 \mathrm{ml}$ of LB supplemented with $100 \mu \mathrm{g} / \mathrm{ml}$ ampicillin. On the subsequent day, $5 \mathrm{ml}$ overnight culture was inoculated into $200 \mathrm{ml}$ fresh medium containing ampicillin and grown until an $\mathrm{OD}_{600}$ of 0.6 was reached. The bacterial pellet was obtained by centrifugation at $6500 \mathrm{rpm}$ for $10 \mathrm{~min}$, resuspended in $4 \mathrm{ml}$ of lysis buffer $(50 \mathrm{mM}$ $\mathrm{NaH}_{2} \mathrm{PO}_{4}$ and $300 \mathrm{mM} \mathrm{NaCl}$ ) with lysozyme $(1 \mathrm{mg} / \mathrm{ml})$ and incubated on ice for $30 \mathrm{~min}$. The suspension was then sonicated with six 10 -s bursts at $200-300 \mathrm{~W}$ with a 10 -s cooling 
period between bursts and centrifuged at $10,000 \mathrm{~g}$ for $25 \mathrm{~min}$ at $4^{\circ} \mathrm{C}$. The supernatant was added to a $50 \% \mathrm{Ni}$-NTA slurry and shaken at $4^{\circ} \mathrm{C}$ for $60 \mathrm{~min}$. The lysate/NiNTA mixture was washed twice with wash buffer $\left(50 \mathrm{mM} \mathrm{NaH} \mathrm{PO}_{4}, 300 \mathrm{mM} \mathrm{NaCl}\right.$, and $10 \mathrm{mM}$ imidazole, $\mathrm{pH} \mathrm{8}$ ) and eluted four times with elution buffer $\left(50 \mathrm{mM} \mathrm{NaH}_{2} \mathrm{PO}_{4}\right.$, $300 \mathrm{mM} \mathrm{NaCl}$, and 250-500 mM imidazole, $\mathrm{pH} 8$ ).

To determine the purity of the Stx2 B subunit, all fractions were diluted $(1: 1)$ in loading buffer (125 mM Tris-HCl, 4\% SDS, $20 \%$ glycerol (v/v), $200 \mathrm{mM} \mathrm{DTT}$, and $0.02 \%$ bromophenol blue, $\mathrm{pH}$ 6.8) and separated on a $12.5 \%$ polyacrylamide gel. One gel was stained with Coomassie blue and the other was electrotransferred to nitrocellulose membranes (Hybond ECL, Amersham Pharmacia Biotech). Membranes were blocked for $30 \mathrm{~min}$ with $1 \%(\mathrm{w} / \mathrm{v})$ bovine serum albumin in phosphate-buffered solution (PBS) at room temperature, and incubated overnight at $4^{\circ} \mathrm{C}$ with the mouse monoclonal antibody (mAb) 13C4 $(10 \mu \mathrm{g} / \mathrm{ml})$ (ATCC, kindly provided by Dr. Ludger Johannes) directed against the Bfragment of Stx1. Membranes were washed with PBS- $0.1 \%$ Tween and incubated for $2 \mathrm{~h}$ at room temperature with goat anti-mouse IgG (Promega; 1:1000) conjugated with alkaline phosphatase. Finally, membranes were washed again as described above and antigen-antibody complexes were visualized with a BCIP/NBT color development substrate according to the manufacturer instructions (Promega).

\section{Stx2 and Stx2 B subunit cytotoxicity to Vero cells}

Culture supernatants from recombinant E. coli containing the Stx2 and Stx2 B subunits were assayed for toxicity to Vero cells (23) at Instituto Nacional de Enfermedades Infecciosas, ANLIS, "Dr. C.G. Malbrán", Buenos Aires. Purified Stx2 holotoxin (Denka Seiken Co., Ltd., Chuo-Ku, Tokyo,
Japan) was also evaluated. The $50 \%$ cytotoxic dose $\left(\mathrm{CD}_{50}\right)$ corresponds to the dilution required to kill $50 \%$ of Vero cells.

\section{Specimen collection and preparation}

After obtaining informed consent, human colon specimens were obtained from organs surgically extracted from adult cancer patients. Immediately after ablation, sections of macroscopically unaffected regions were placed in ice-cold high $\mathrm{K}^{+}$-Ringer solution $(120 \mathrm{mM} \mathrm{KCl}, 10 \mathrm{mM} \mathrm{NaHCO} 3,1.2$ $\mathrm{mM} \mathrm{MgCl}_{2}, 1.2 \mathrm{mMCaCl}_{2}, 1.2 \mathrm{mMK}_{2} \mathrm{HPO}_{4}$, $0.2 \mathrm{mM} \mathrm{KH}_{2} \mathrm{PO}_{4}$, and $25 \mathrm{mM}$ glucose) to preserve the transport functions (14). The mucosa and submucosa layers were then dissected from underlying tissue (kept at $4^{\circ} \mathrm{C}$ ) and mounted as a diaphragm in a modified Ussing chamber $\left(1.76 \mathrm{~cm}^{2}\right)$. Rat colon specimens were surgically obtained from male Sprague Dawley rats weighing approximately $100 \mathrm{~g}$ and were immediately mounted on the Ussing chamber $\left(0.94 \mathrm{~cm}^{2}\right)$.

Both sides of the tissue were then bathed with standard Ringer solution and bubbled with $95 \% \mathrm{O}_{2}-5 \% \mathrm{CO}_{2}$. The bathing solution was maintained at $37^{\circ} \mathrm{C}$ with water-jacketed reservoirs connected to a constant-temperature circulating pump. The Ussing chamber model used consisted in fact of two chambers, each with a mucosal and serosal compartment divided by the mounted tissue.

\section{Net water flux and electrical measurements}

Transepithelial net water flux (Jw) was recorded automatically with an Ussing chamber connected to a special electro-optical device. Briefly, the tissue was held against a nylon mesh by applying a hydrostatic pressure of $10 \mathrm{~cm}$ of $\mathrm{H}_{2} \mathrm{O}$. Water movement across the tissue was measured by displacement of a photo-opaque solution inside a glass capillary tube connected to the mucosal side of the chamber via an intermediate chamber. The liquid meniscus movement in 
the glass capillary was detected using the electro-optical device connected to a computer. Data are obtained with an accuracy of $50 \mathrm{nl}$.

The spontaneous potential difference was recorded in the other chamber across the calomel electrodes, via agar bridges placed adjacent to the epithelium under open-circuit conditions. The short circuit current was measured with an automatic voltage clamp system that kept the potential difference at zero $\mathrm{mV}$.

Once the tissue reached steady values, $200 \mu 1$ of culture supernatant from different E. coli recombinants or different concentrations of purified Stx $2 \mathrm{~B}$ subunit was added to the mucosal bath (time 0). Variations in Jw and short circuit current were continuously measured for at least $60 \mathrm{~min}$. Because of tissue variability, data are presented as $\Delta \mathrm{Jw}$, where $\Delta \mathrm{JW}=\mathrm{JW}$ at time $\mathrm{t}-\mathrm{JW}$ at time 0 .

For the inhibition test, $200 \mu 1$ of each culture supernatant containing the Stx 2 or Stx2 B subunit was mixed with an equal volume of $\mathrm{mAb} 13 \mathrm{C} 4(20 \mu \mathrm{g} / \mathrm{ml})$ and incubated for $30 \mathrm{~min}$ at $37^{\circ} \mathrm{C}$ before being added to the Ussing chamber.

\section{Animal experimentation}

A total of 21 male Sprague Dawley rats weighing 100-150 g were used in this study. The rats were fasted overnight and then anesthetized for surgery with an intramuscular injection of $100 \mu \mathrm{g}$ ketamine/g body weight and $10 \mu \mathrm{g}$ diazepam/g body weight. Body temperature was kept at $37^{\circ} \mathrm{C}$ by a lamp. The abdominal cavity was opened by a midline incision and three $2-\mathrm{cm}$ long colon segments (loops) separated by 1-cm interloops were prepared in each rat. Colon loops were then inoculated intraluminally with either $300 \mu \mathrm{l}$ of culture supernatants from $E$. coli (control) and from E. coli (pStx2) or E. coli (pStx2B) containing approximately $24 \mathrm{ng}$ of the B subunit. In selected experiments, colon loops were inoculated with either buffered saline (control loops) and $3 \mathrm{ng} / \mathrm{ml}$ of commercially purified Stx 2 holotoxin or 3 and $30 \mathrm{ng} / \mathrm{ml}$ of Stx2 B subunit purified by us. The order of inoculation of the colon loops was randomized for each rat and the animals were killed by cervical dislocation $16 \mathrm{~h}$ after inoculation. Colon loops were rapidly removed, measured for length and fluid content, and prepared for histochemistry.

Light microscopy, fixation and histochemistry

Fragments of human and rat colon recovered $60 \mathrm{~min}$ after toxin addition were prepared for histochemistry. Tissues were fixed for at least $24 \mathrm{~h}$ in cold fixative $\left(4^{\circ} \mathrm{C}\right)$ containing 4\% formaldehyde in PBS (145 mM $\mathrm{NaCl} / 10 \mathrm{mM} \mathrm{NaH}{ }_{2} \mathrm{PO}_{4}, \mathrm{pH}$ 7.2). After fixation, longitudinal 6-8- $\mu \mathrm{m}$ thick sections were cut, dehydrated, and carefully embedded in paraffin to provide sections perpendicular to the mucosa. Sections were then stained with hematoxylin-eosin and examined by light microscopy.

The colon loops were opened along their anti-mesenteric margins, pinned to a paraffin plate, fixed and stained as described above. Each tissue section was examined by an observer unaware of the treatment status.

\section{Statistical analysis}

Results are reported as means \pm SEM. The statistical significance between two mean values obtained for two experimental conditions was calculated by the Student $t$-test. All data from the curves were analyzed by oneway analysis of variance (ANOVA). P values $<0.05$ were taken as significant.

\section{Results}

\section{Stx2 B subunit expression and purification}

The Stx2 B subunit was purified by metalaffinity chromatography and in SDS-PAGE. 
Two bands of approximately $7.5 \mathrm{kDa}$ and 38 $\mathrm{kDa}$ were observed in the third eluted fraction (Figure 1, left). These bands correspond to the more stable conformations, i.e., monomeric and pentameric, described for StxB (24). The identity of the Stx2 B subunits was confirmed by immunoblotting (Figure 1, right). The quantity of the Stx2 B subunit was determined by densitometry of the pro-
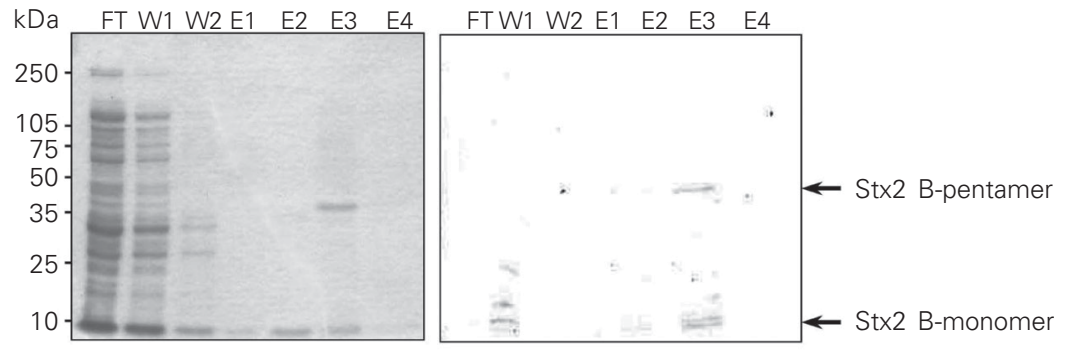

Figure 1. SDS-PAGE analysis of the Stx2 B subunit purified by affinity chromatography under native conditions. The Stx2 B subunit was expressed from the pQE-70 vector in $\mathrm{DH} 5 \alpha$ E. coli cells and purified on Ni-NTA agarose with the indicated imidazole concentrations in the wash and elution steps. Proteins were visualized by Coomassie blue staining (left side) and developed by Western blots (right side) using the mouse mAb 13C4 (10 $\mu \mathrm{g} /$ $\mathrm{ml}) . \mathrm{FT}=$ flow-through; $\mathrm{W} 1$ and $\mathrm{W} 2=10 \mathrm{mM}$ imidazole wash; E1, E2 and E3 = $250 \mathrm{mM}$ imidazole elution; E4 = 500 mM imidazole elution.

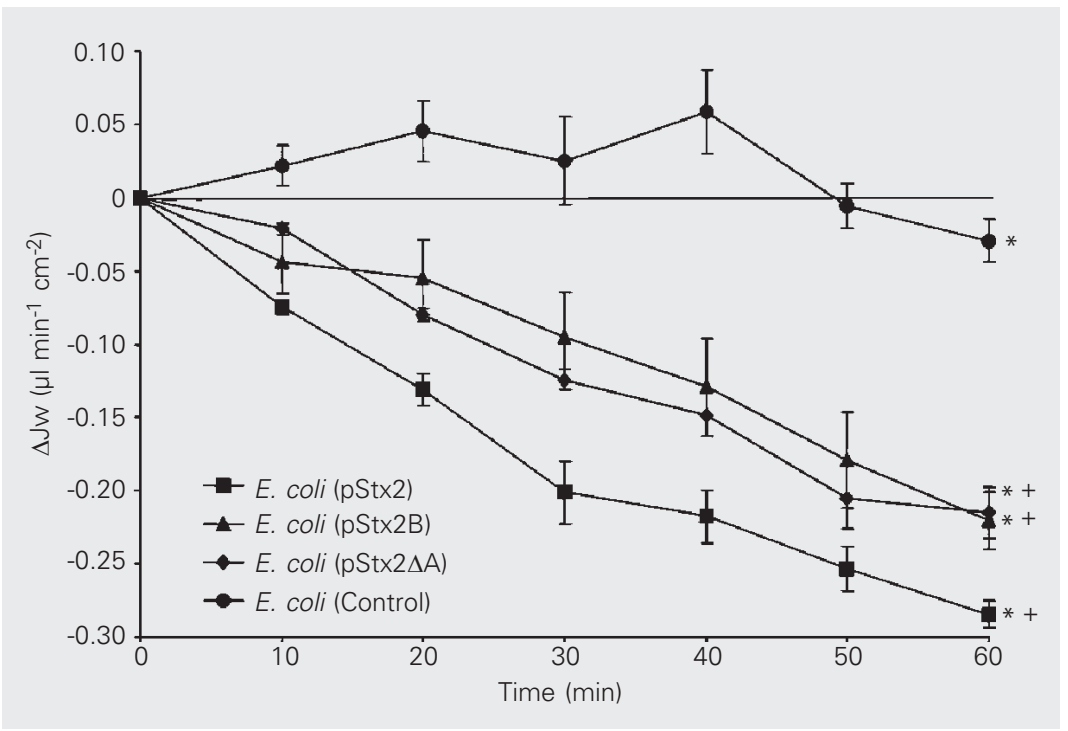

Figure 2. Effect of E. coli (pStx2), E. coli (pStx2B), E. coli (pStx2 $\Delta \mathrm{A})$, and E. coli (control) on transepithelial net water flux $(\Delta \mathrm{JW})$ in human colon. At time zero, $200 \mu \mathrm{l}$ of supernatants from E. coli (pStx2), E. coli ( $\mathrm{pSt} \times 2 \mathrm{~B})$, E. coli $(\mathrm{pSt} \times 2 \Delta \mathrm{A})$, and E. coli (control) were added to the mucosal bath. Each point indicates the mean \pm SEM of 3 to 8 experiments. ${ }^{*} P<0.001$ for $E$. coli $(\mathrm{pSt} \times 2)$, E. coli $(\mathrm{pSt} \times 2 \mathrm{~B})$ and $E$. coli $(\mathrm{pSt} \times 2 \Delta \mathrm{A})$ vs control. ${ }^{+\mathrm{P}}<0.05$ for $E$. coli

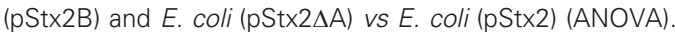

tein bands on the nitrocellulose membrane using $B$-actin as a reference standard. This purification procedure routinely resulted in approximately $150 \mu \mathrm{g}$ Stx 2 B subunit purified to at least $97 \%$ homogeneity from a 1 liter culture.

The average yield of B subunit in overnight cultures from recombinant $E$. coli (pStx2), E. coli (pStx2B) and E. coli (pStx $2 \Delta \mathrm{A})$, calculated by comparison with known amounts of Stx2 B subunit, was approximately $80 \mathrm{ng} / \mathrm{ml}$.

\section{Cytotoxicity of the Stx2 and Stx2 B subunits to Vero cells}

The cytotoxicity of overnight culture supernatants from $E$. coli containing the Stx2 or Stx2 B subunit was assayed on Vero cells. The $\mathrm{CD}_{50}$ of crude $\mathrm{Stx} 2$ was $0.4 \mathrm{pg} / \mathrm{ml}$, which is consistent with previous values obtained with culture supernatants from E. coli C600 (933W) (14). In contrast, the crude Stx2 B subunit was non-toxic to Vero cells at $\leq 1 \mu \mathrm{g}$ / $\mathrm{ml}$. These results are consistent with data for the cloned Stx2 B subunit reported by Marcato et al. (19).

\section{Effect of the Stx2 B subunit on colonic mucosa mounted on an Ussing chamber}

Under basal conditions, a net absorptive $\mathrm{JW}$ was observed in human intestine placed between two identical Ringer solutions in the Ussing chamber. After an initial stabilization period, $200 \mu 1$ of culture supernatant from E. coli (pStx2) containing Stx2 was added to the mucosal bath $(\mathrm{t}=0)$. Stx2 induced a significant $\mathrm{Jw}$ inhibition (Figure 2 ), whereas short circuit current remained unchanged during at least $60 \mathrm{~min}$ of incubation (data not shown).

The absorptive Jw was also reduced by supernatants from $E$. coli (pStx2B) and $E$. coli $(\mathrm{pStx} 2 \Delta \mathrm{A})$ which contain the Stx 2 B subunit at the same concentration $(4 \mathrm{ng} / \mathrm{ml})$ as that present in the supernatants from $E$. 
coli (pStx2) (Figure 2). However, these effects were less marked, showing the contribution of the Stx2 A subunits to the mechanisms involved in water transport inhibition.

An absorptive Jw inhibition was also observed when rat colon mounted on an Ussing chamber was treated with supernatants from E. coli (pStx2) and E. coli (pStx2B) (Figure 3). However, this inhibition was dramatically reduced when culture supernatants were pretreated with $\mathrm{mAb} 13 \mathrm{C} 4(20 \mu \mathrm{g} / \mathrm{ml})$ (Figure 3). mAb 13C4, by itself, had no effect on the absorptive Jw and was included as a negative control (Figure 3).

JW inhibition depended on Stx2 B subunit concentration (Figure 4). The timecourse of inhibition by $400 \mathrm{ng} / \mathrm{ml}$ of the Stx 2 B subunit was similar to that obtained using $12 \mathrm{ng} / \mathrm{ml}$ of purified Stx 2 holotoxin, suggesting that both the A and B subunits of Stx2 contribute to the inhibition of the absorptive Jw by independent mechanisms.

Compared with the data obtained for $E$. coli (pStx2B) supernatants, a 50-fold higher dose of the purified Stx2 B subunit was required to inhibit the absorptive $\mathrm{Jw}$ to the same level as that observed using supernatants expressing the Stx2 B subunit (compare Figures 3 and 4). These differences may be attributed to other endotoxins present in the bacterial supernatants that might act synergistically with the Stx2 B subunit to inhibit water absorption.

\section{Histopathological analysis of the colonic mucosa}

Colonic mucosa treated in vitro with crude and purified Stx2 (12 ng/ml) for $60 \mathrm{~min}$ revealed a moderate lesion in human $(\mathrm{N}=3)$ and $\operatorname{rat}(\mathrm{N}=4)$ colon. Purified Stx 2 holotoxin caused a lesion of colonic mucosa with destruction of surface epithelium, marked mucin depletion, and moderate neutrophil infiltration, in agreement with previous data (14). In contrast, at $400 \mathrm{ng} / \mathrm{ml}$, the crude and purified Stx2 B subunits had no effect on the macro- or microscopic appearance of human colon $(\mathrm{N}=4)$ or rat colon $(\mathrm{N}=5)$, as did the PBS control on human colon $(\mathrm{N}=4)$ or rat colon $(\mathrm{N}=8)$.

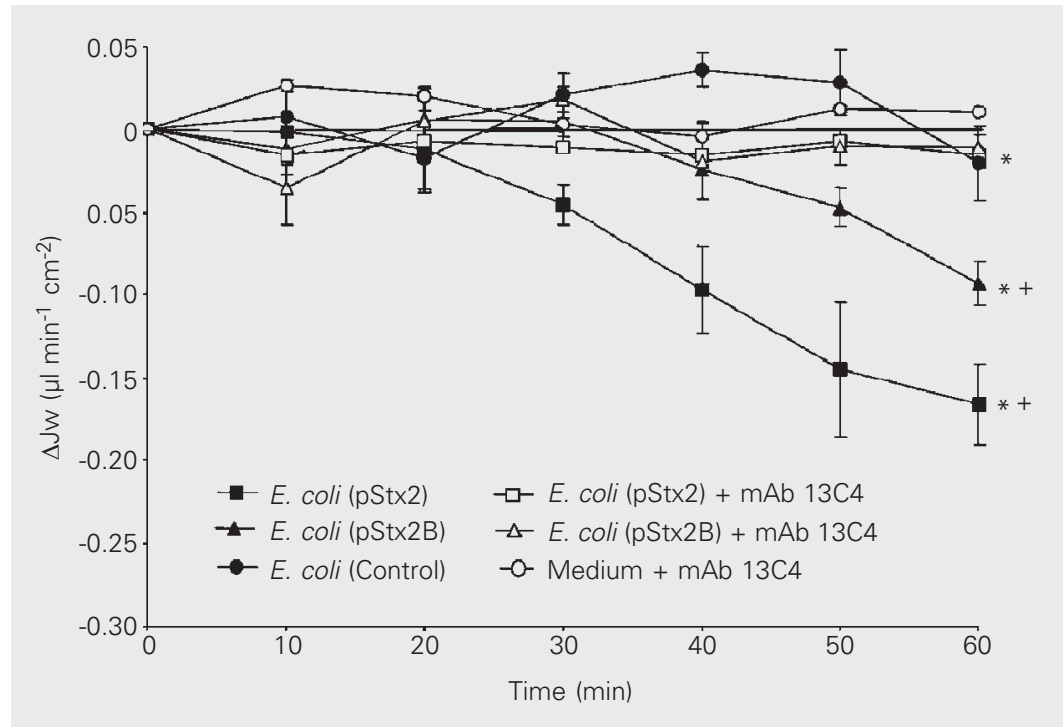

Figure 3. Inhibition of pStx2- and pStx2B-induced transepithelial net water flux (Jw) on rat colon by the mouse mAb $13 \mathrm{C} 4$. E. coli $(\mathrm{pSt} \times 2)$ and E. coli $(\mathrm{pSt} \times 2 \mathrm{~B})$ supernatants were preincubated with an equal volume of mAb $13 \mathrm{C} 4(20 \mu \mathrm{g} / \mathrm{ml})$ for $30 \mathrm{~min}$ at $37^{\circ} \mathrm{C}$. The antigenantibody complex was then added to the mucosal bath. Control consisted of non-inoculated culture medium plus mAb 13C4 $(20 \mu \mathrm{g} / \mathrm{ml})$. Each point indicates the mean $\pm \mathrm{SEM}$ of 3 to 8 experiments. ${ }^{*} \mathrm{P}<0.001$ for $E$. coli $(\mathrm{pSt} \times 2)$ and $E$. coli $(\mathrm{pSt} \times 2 \mathrm{~B})$ vs $E$. coli (control). ${ }^{+} \mathrm{P}<$ 0.001 for $E$. coli (pStx2) vs E. coli (pStx2B) (ANOVA)

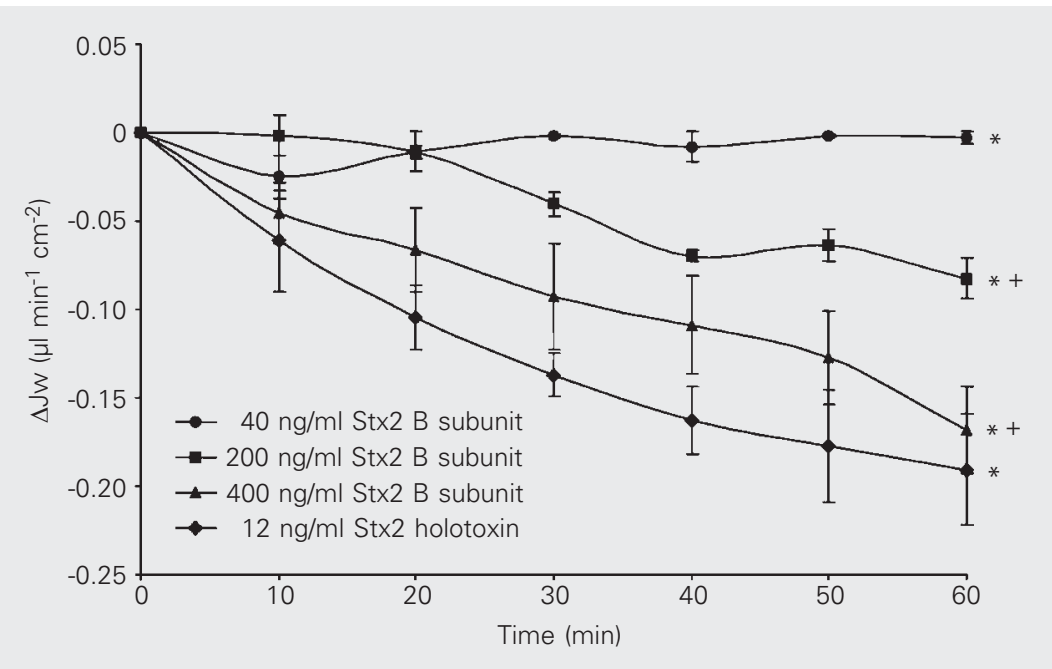

Figure 4. Effect of Stx2 B subunit and Stx2 holotoxin on transepithelial net water flux ( $\Delta \mathrm{Jw})$ in rat colon. Colonic mucosa was incubated at $37^{\circ} \mathrm{C}$ for 60 min with the indicated concentrations of the Stx2 B subunit or $12 \mathrm{ng} / \mathrm{ml}$ of Stx2 holotoxin. Data are reported as means \pm SEM of at least 3 experiments. ${ }^{*} \mathrm{P}<0.001$ for Stx2 holotoxin, $12 \mathrm{ng} / \mathrm{ml}$, and Stx2 B subunit, 200 and $400 \mathrm{ng} / \mathrm{ml}$ vs Stx2 B $40 \mathrm{ng} / \mathrm{ml}$ (ANOVA). ${ }^{+} \mathrm{P}<0.001$ for Stx2 B subunit, $200 \mathrm{ng} / \mathrm{ml}$ vs $400 \mathrm{ng} / \mathrm{ml}$ (ANOVA). 


\section{Analysis of the effects of the Stx2 and Stx2 B subunits using rat colon loops}

The effects of either culture supernatants from E. coli $(\mathrm{pStx} 2)$ and E. coli $(\mathrm{pStx} 2 \mathrm{~B})$ or purified Stx2 holotoxin and Stx2 B subunit were studied in colon loops $16 \mathrm{~h}$ after inoculation. The most severe lesions were observed with the use of Stx2. Grossly, after 16 $\mathrm{h}$ of treatment, the loops were distended and filled with abundant hemorrhagic fluid (Table

\begin{tabular}{|c|c|c|c|}
\hline $\begin{array}{l}16-h \text { incubation with } \\
\text { culture supernatants } \\
\text { from }\end{array}$ & $\begin{array}{l}\text { Fluid accumulation } \\
\qquad(\mu \mathrm{l} / \mathrm{cm})\end{array}$ & $\begin{array}{c}\text { 16-h incubation with } \\
\text { purified Stx2 or } \\
\text { vehicle }\end{array}$ & $\begin{array}{l}\text { Fluid accumulation } \\
\qquad(\mu \mathrm{l} / \mathrm{cm})\end{array}$ \\
\hline E. coli (control) & $\mathrm{IF}^{\mathrm{a}}(6)$ & PBS (control) & $\mathrm{IF}^{\mathrm{a}}(8)$ \\
\hline E. coli (pStx2) & $645 \pm 23(2)$ & Holotoxin $3 \mathrm{ng} / \mathrm{ml}$ & $553 \pm 22(3)$ \\
\hline E. coli (pStx2B) & $254 \pm 16^{*}(5)$ & $\begin{array}{l}3 \mathrm{ng} / \mathrm{ml} \\
30 \mathrm{ng} / \mathrm{ml}\end{array}$ & $\begin{array}{l}173 \pm 13^{*}(3) \\
222 \pm 15^{*}(2)\end{array}$ \\
\hline
\end{tabular}

Data are reported as means \pm SEM for fluid accumulation by colon loops treated with the crude or purified Stx2 and Stx2 B subunits. The number of experiments is indicated in parentheses. alnsignificant amount of fluid present. ${ }^{*} \mathrm{P}<0.001$ compared to Stx2 (Student $t$-test).
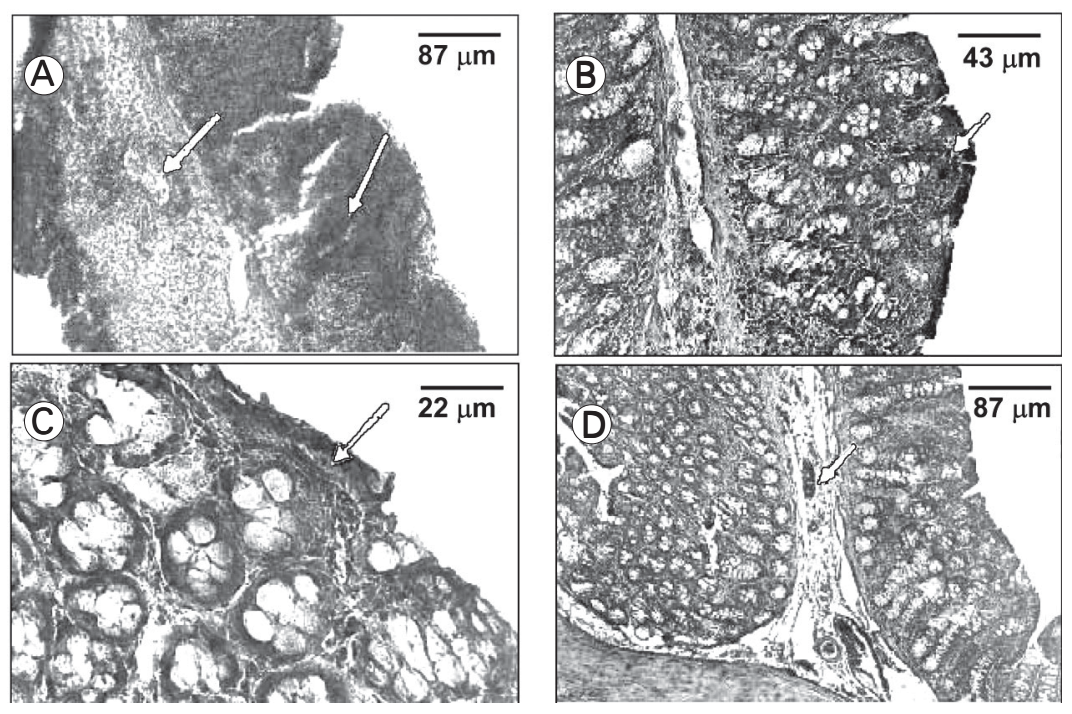

Figure 5. Rat colon loops treated with the Stx2 (A) or Stx2 B subunit (B and C) at $16 \mathrm{~h}$ of incubation (hematoxylin-eosin). The Stx2 B subunit produced subapical vascular congestion (yellow arrows) compared to control (D). In contrast, Stx2 produced distortion of the histoarchitecture because of extensive necrotic and hemorrhagic areas (white arrow) and marked edema and vascular congestion in the submucosa (green arrow)
1). The serosal surfaces of these loops were hemorrhagic. In turn, the crude and purified Stx2 B subunit produced a non-hemorrhagic fluid accumulation in a concentration-dependent manner. The purified Stx2 B subunit caused a more significant fluid accumulation at $30 \mathrm{ng} / \mathrm{ml}$ than at $3 \mathrm{ng} / \mathrm{ml}$ (Table 1).

Histologically, the Stx2 B subunit produced marked vascular congestion and a micro-hemorrhagic focus in the mucosa (Figure $5 \mathrm{~B}$ and $\mathrm{C}$ ) compared to control (Figure $5 \mathrm{D})$, whereas Stx2 produced extensive necrotic areas containing hematic material (Figure $5 \mathrm{~A}$ ). Moreover, many of the degenerating absorptive cells were being extruded from the villi, and the intestinal lumen was filled with numerous dead and degenerating epithelial cells including erythrocytes (Figure $5 \mathrm{~A}$ ).

\section{Discussion}

Two features of the clinical syndrome caused by STEC suggest the importance of the effects of Stx on the epithelial cells of the distal small intestine and colon. STEC infection can result in fever, malaise, abdominal cramps, and hemorrhagic diarrhea $(25,26)$.

The purpose of the present investigation was to study the ability of the Stx2 B subunit to produce physiological and morphological changes in human and rat colon.

We detected the biological effects of the Stx2 B subunit on colonic mucosa both in vitro and in vivo. The Stx2 B subunit inhibited water absorption across the human and rat colonic mucosa mounted on an Ussing chamber, while Stx2 showed highly significant water absorption inhibition concomitant with morphological damage in colonic surface cells including an inflammatory response. These findings contrast with those published by Li et al. (27), which showed that the effects of E. coli $\mathrm{O} 157: \mathrm{H} 7$, using rabbit colon, on ion and water fluxes were independent of Stx production. In the present experiments, however, the effects were 
dramatically reduced by neutralization with $\mathrm{mAb} 13 \mathrm{C} 4$, indicating a specific action of the Shiga toxin on colonic mucosa. Histological alterations in colonic epithelial cells caused by the Stx 2 but not the Stx2 B subunit at $1 \mathrm{~h}$ of incubation confirm the important role of the Stx2 A subunit in cell necrosis as a result of protein synthesis inhibition. The dose of purified Stx2 B subunit (200 ng/ml) necessary to inhibit water absorption across the rat colon at the same level as the culture supernatant containing the Stx2 B subunit (4 $\mathrm{ng} / \mathrm{ml}$ ) was 50 -fold higher. These results suggest that additional bacterial factors present in the culture supernatants may potentiate the biological action of the Stx2 B subunit.

The Stx2 and Stx2 B subunits inhibit water absorption with no effect on the short circuit current. NaCl-coupled absorption has been described in the human colon and a water movement associated with an electroneutral absorption of $\mathrm{Na}^{+}$has also been reported (28). Our finding that the Stx2 B subunit inhibits water absorption without altering the electrical parameters is consistent with the hypothesis that an electrogenically silent transport system coupled to water absorption could be affected by the Stx 2 B subunit, causing the watery diarrhea sometimes seen in STEC infections. However, we cannot rule out the possibility that these effects are due to apoptosis since Stx1B and Stx2B have been reported to trigger apoptosis, albeit after more than $1 \mathrm{~h}$, in Burkitt's lymphoma B cells $(16,17)$. Further experiments will be necessary to identify the membrane transporter specifically affected by the Stx2 B subunit, presumably in absorptive epithelial cells.

The results obtained here with rat colon loops also provide evidence for a role of the Stx2 B subunit in causing watery diarrhea. Stx2 produced hemorrhagic fluid accumulation and histological damage in colon loops while the Stx2 B subunit caused a non-hemorrhagic fluid accumulation after $16 \mathrm{~h}$ of incubation. One can therefore propose that the Stx2 B subunit induces fluid accumulation by altering the usual balance of intestinal absorption and secretion toward net secretion. The fact that the secretory activity of Stx 2 is hemorrhagic and by far exceeds that of the Stx2 B subunit could be a consequence of the vascular damage associated with Stx2 (26).

In view of the reported immunoprophylactic potential of the Stx2 B subunit and of its proposed use as a component in an acellular STEC vaccine (19) or as a vector in DNA (29) and cancer vaccines $(30,31)$, further studies will be necessary to determine whether the biological activity of the Stx2 B subunit may have pathogenic consequences when it is used as a vaccine.

\section{Acknowledgments}

The authors thank Germán Chillemi, Instituto Nacional de Enfermedades Infecciosas ANLIS "Dr. Carlos. G. Malbrán", for help with the Vero cytotoxicity assays; Mercedes Pistone Creydt for providing human colon fragments from Hospital "Bernardo Rivadavia", Buenos Aires, Argentina; Eric Tartour, Hôpital Européen George Pompidou, Paris, France, for helpful suggestions, and Ludger Johannes, Institut Curie, Paris, France, for kindly providing the monoclonal antibody $13 \mathrm{C} 4$ directed against the $\mathrm{B}$-fragment of Shiga toxin. 


\section{References}

1. Griffin PM \& Tauxe RV (1991). The epidemiology of infections caused by Escherichia coli 0157:H7, other enterohemorrhagic E. coli, and the associated hemolytic uremic syndrome. Epidemiologic Reviews, 13: 60-98.

2. Richardson SE, Karmali MA, Becker LE \& Smith CR (1988). The histopathology of the hemolytic uremic syndrome associated with verocytotoxin-producing Escherichia coli. Human Pathology, 19: $1102-1110$.

3. López EL, Díaz M, Grinstein S et al. (1989). Hemolytic uremic syndrome and diarrhea in Argentine children: the role of Shiga-like toxins. Journal of Infectious Diseases, 160: 469-475.

4. Rivas M, Balbi L, Milliwebsky E, García B, Tous M, Leardini N, Prieto M, Chillemi G \& De Principi M (1998). Síndrome urémico hemolítico en niños de Mendoza, Argentina: Su asociación con la infección por Escherichia coli productor de toxina Shiga. Medicina, 58: 1-7.

5. Cohen A, Hannigan GE, Williams BRG \& Lingwood CA (1987). Roles of globotriosyl- and galabiosylceramide in verotoxin binding and high affinity interferon receptor. Journal of Biological Chemistry, 262: 17088-17099.

6. Sandvig K, Olsnes S, Brown JE, Petersen OW \& van Deurs B (1989). Endocytosis from coated pits of Shiga toxin: a glycolipidbinding protein from Shigella dysenteriae 1. Journal of Cell Biology, 108: 1331-1343.

7. Obrig TG, Moran TP \& Brown JE (1987). The mode of action of Shiga toxin on peptide elongation of eukaryotic protein synthesis. Biochemical Journal, 244: 287-294.

8. Ching JC, Jones NL, Ceponis PJ, Karmali MA \& Sherman PM (2002). Escherichia coli Shiga-like toxins induce apoptosis and cleavage of poly (ADP-ribose) polymerase via in vitro activation of caspases. Infection and Immunity, 70: 4669-4677.

9. Jones NL, Islur A, Haq R, Mascarenhas M, Karmali MA, Perdue MH, Zanke BW \& Sherman PM (2000). Escherichia coli Shiga toxin induces apoptosis in epithelial cells that is regulated by the Bcl-2 family. American Journal of Physiology, 278: 811-819.

10. Abreu MT, Palladino AA, Arnold ET, Kwon RS \& McRoberts JA (2000). Modulation of barrier function during Fas-mediated apoptosis in human intestinal epithelial cells. Gastroenterology, 119: 15241536.

11. Acheson DWK, Moore R, De Breucker S, Lincicome L, Jacewicz M, Skutelsky E \& Kelusch GT (1996). Translocation of Shiga toxin across polarized intestinal cells in tissue culture. Infection and Immunity, 64: 3294-3300.

12. Rodney A, Moxley L \& Francis DH (1998). Overview of animal models. In: Kaper JB \& O'Brien AD (Editors), Escherichia coli 0157:H7 and other Shiga Toxin-Producing E. coli Strains. American Society for Microbiology, Washington, DC, USA.

13. Keenan KP, Sharpnack DD, Collins H, Formal SB \& O'Brien AD (1986). Morphologic evaluation of the effects of Shiga toxin and $E$. coli Shiga-like toxin on the rabbit intestine. American Journal of Pathology, 125: 69-80.

14. Fiorito P, Burgos JM, Miyakawa MF, Rivas M, Chillemi G, Berkowski D, Zotta E, Silberstein C \& Ibarra C (2000). Effect of Shiga toxin 2 on water and ion transport in human colon in vitro. Digestive Diseases and Sciences, 45: 480-486

15. Pistone Creydt V, Miyakawa MF, Martín F, Zotta E, Silberstein C \& Ibarra C (2002). La subunidad B de Stx2 enterohemorrágica tiene efecto citotóxico sobre colon y riñón humano. XVI Congreso
Latinoamericano de Microbiología, La Habana, Cuba, 14 (Symposium).

16. Mangeney M, Lingwood CA, Taga S, Caillou B, Tursz $T$ \& Wiels $J$ (1993). Apoptosis induced in Burkitt's lymphoma cells via Gb3/ CD77, a glycolipid antigen. Cancer Research, 53: 5314-5319.

17. Marcato P, Mulvey G \& Armstrong GD (2002). Cloned Shiga toxin 2 B subunit induces apoptosis in Ramos Burkitt's lymphoma B cells. Infection and Immunity, 70: 1279-1286.

18. Calderwood SB, Acheson DW, Goldberg MB, Boyko SA \& DonohueRolfe A (1990). A system for production and rapid purification of large amounts of the Shiga toxin/Shiga-like toxin I B subunit. Infection and Immunity, 58: 2977-2982.

19. Marcato P, Mulvey G, Read RJ, Helm KV, Nation PN \& Armstrong GD (2001). Immunoprophylactic potential of cloned Shiga toxin 2 B subunit. Journal of Infectious Diseases, 183: 435-443.

20. Kojio S, Zhang H, Ohmura M, Gondaira F, Kobayashi N \& Yamamoto T (2000). Caspase-3 activation and apoptosis induction coupled with the retrograde transport of Shiga toxin: inhibition by brefeldin A. FEMS Immunology and Medical Microbiology, 29: 275-281.

21. Sambrook J, Fritsch EF \& Maniatis T (1989). Molecular Cloning: A Laboratory Manual. Cold Spring Harbor Laboratory Press, Cold Spring Harbor, NY, USA.

22. Newland JW, Strockbine NA, Miller SF, O'Brien AD \& Holmes RK (1985). Cloning of Shiga-like toxin converting phage of Escherichia coli. Science, 230: 179-181.

23. Karmali MA, Petric M, Lim C, Cheung R \& Arbur GS (1985). The association between hemolytic uremic syndrome and infection by Verotoxin producing Escherichia coli. Journal of Infectious Diseases, 151: 775-782

24. Pina DG, Gomez J, Villar E, Johannes L \& Shanyrov L (2003). Thermodynamic analysis of the structural stability of the Shiga toxin B subunit. Biochemistry, 42: 9498-9506.

25. Riley LW, Remis RS, Helgerson SD et al. (1983). Hemorrhagic colitis associated with a rare Escherichia coli serotype. New England Journal of Medicine, 308: 681-685.

26. Nataro JP \& Kaper JB (1998). Diarrheagenic Escherichia coli. Clinical Microbiology Reviews, 11: 142-201.

27. Li Z, Bell C, Buret A, Robins-Browne R, Stiel D \& O'Loughlin E (1993). The effect of enterohemorrhagic Escherichia coli O157:H7 on intestinal structure and solute transport in rabbits. Gastroenterology, 104: 467-474

28. Kunzelmann K \& Mall M (2002). Electrolyte transport in the mammalian colon: mechanisms and implications for disease. Physiological Reviews, 82: 245-289

29. Capozzo AB, Pistone V, Dran G, Fernandez G, Gomez S, Bentancor L, Rubel C, Ibarra C, Isturiz M \& Palermo M (2003). Development of DNA vaccine against hemolytic uremic syndrome in a murine model. Infection and Immunity, 71: 3971-3978.

30. Haicheur N, Bismuth E, Bosset S et al. (2000). The B subunit of Shiga toxin to a tumor antigen elicits CTL and targets dendritic cells to allow MHC class I-restricted presentation of peptides derived from exogenous antigens. Journal of Immunology, 165: 3301-3308.

31. Lee RS, Tartour E, van der Bruggen P, Vantomme V, Joyeux I, Goud $B$, Fridman WH \& Johannes L (1998). Major histocompatibility complex class I presentation of exogenous soluble tumor antigen fused to the B-fragment of Shiga toxin. European Journal of Immunology, 28: $2726-2737$ 